\title{
Do Micro Health Insurance Units Need Capital or Reinsurance? A Simulated Exercise to Examine Different Alternatives
}

\author{
David M. Dror and John Armstrong \\ rte de Frontenex 39b, CH-1207 Geneva, Switzerland. \\ E-mail: daviddror@socialre.org,johnarmstrong@eircom.net
}

The purpose of this article is to provide a technical discussion of capital loading that "micro health insurance units" (MIUs) must add to the premium to maintain financial sustainability. MIUs offer benefit packages and require prepayment, that is, they create a rudimentary community-based health insurance for poor people in low-income countries. We broke up the 2001 data set of a health insurer containing upward of 1.3 million insureds into 535 "virtual MIUs"; and running 1,005 iterations, we got a data yield of 537,675 virtual MIUs. Capital loading levels increased steeply with decreasing group size and higher confidence levels. The impact of group size remains strong even with groups of 25,000 plus, and is stronger than the impact of changes in confidence levels. We discuss options to correct size-related premium bias through government subsidies, and conclude that reinsurance is cheaper than capital loading and a preferable solution for governments compared to other alternatives.

The Geneva Papers (2006) 31, 739-761. doi:10.1057/palgrave.gpp.2510107

Keywords: reinsurance; capital requirement; health insurance; micro health insurance units; social reinsurance; low-income countries

\section{Introduction}

The purpose of this article is to provide a technical basis for the discussion, both among market innovators in the insurance industry and among policy-makers, of financial sustainability of nascent insurance mechanisms that emerge at grassroots level in low-income countries, known as "micro health insurance units" (MIUs).

One of the limiting factors for extension of health insurance in low-income countries is the price of the premium. It is clear that the premium must reflect the aggregate risk borne by the insurer, regardless of the rating method applied. However, insurance premiums normally cover much more than the cost of the pure risk, as they must include capital loading (reflecting the cost associated with regulatory surplus requirements and with uncertainty of the risk calculations) and loading for administration (reflecting transaction costs associated with product design, premium

\footnotetext{
* This article incorporates elements from an earlier partial version (Dror et al., 2005a). The calculations presented here differ from previous findings as they are based on a new and much larger set of iterations of the empirical data, and a complete revision of the text, tables, figures and references. Useful comments of four anonymous peer reviewers are gratefully acknowledged.
} 
collection, cost of reinsurance and profits). The loadings for operational and business risks such as mispricing of underwriting and claims adjudication can be both large and difficult to measure (they are not dealt with here). Additionally, the technical assumptions used to determine profit are not always stated. Therefore, many riskbased capital models include large loads over the measurable statistical fluctuations (in the order of two to three times or more). In most low- and middle-income countries, this practice nourishes a perception that insurance premiums prioritize profits of rich insurers over protecting poor clients from financial havoc, and could thus be excessive and unfair. Hence, a reasoned discussion of loading to insurance premiums can contribute to transparency, credibility, understanding and acceptance of insurance practices, and by extension to insurance penetration in low-income countries as well as to "making insurance work for the poor".

Additionally, in many low-income countries health insurance is increasingly sold by or through community-based groups, also known as MIUs. In terms of insurance modeling, MIUs represent a multitude of fragmented, relatively small sub-pools, which are not combined into one large set. We seek to investigate the capital needs of MIUs to cover outlier costs, comparing alternative solutions, in particular own capital and reinsurance, bearing in mind the impact of the fragmentation on capital loading. This is done through a simulation exercise, which enables us to compare the capital requirements of one large pool with the capital requirements of many small sub-pools of varying sizes. The many small sub-pools are treated here as "virtual micro health insurance units" (virtual MIUs).

The article is structured as follows: the first section offers a short overview of why MIUs are of interest, their role, impact and estimated outreach today. The following section presents the methods employed in this study, and the next section provides the findings of the simulation. The following section contains the discussion of the findings, followed by a discussion of whether reinsurance can be an alternative to capital loading, and potential advantages of this alternative. The article then presents the limitations of the model, and in the last section it offers the authors' policy conclusions.

\section{Background information on micro health insurance in low-income countries}

The phenomenon of insuring by or through MIUs is relatively new but by no means negligible. The attraction to deal with MIUs finds its origin in the thought that, just as micro finance enabled poor people to gain access to capital, micro insurance might provide the platform to make health insurance work for the poor. The term "micro insurance" can be found in the literature for the first time in $1999,{ }^{1}$ but other terms have also been used before and since, including community-based health financing schemes, mutual health insurance schemes, etc. ${ }^{2}$ In the last few years there has been new published research on the strength of MIUs in gaining clients' trust, based on the social capital of the group. ${ }^{3}$ Several inventories of MIUs suggest that they have

\footnotetext{
${ }^{1}$ Dror and Jacquier (1999)

${ }^{2}$ Atim et al. (2005); Derriennic et al. (2005)

${ }^{3}$ Preker et al. (2002); Burdine et al. (1999)
} 
developed mainly in West Africa, ${ }^{4}$ in India, ${ }^{5}$ Philippines, ${ }^{6}$ and Bangladesh, ${ }^{7}$ although quite a few MIUs operate also in other South Asian countries (e.g., Nepal ${ }^{8}$ ) and elsewhere. ${ }^{9}$ Overall outreach is now counted in the millions of insureds. ${ }^{10}$ Much of the literature looks at MIUs as health systems: for example, what impact do MIUs have on access to healthcare, ${ }^{11}$ or how well do these bodies perform in terms of equality of access among members, ${ }^{12}$ their contribution to capturing additional resources for healthcare,,$^{13}$ on expressed willingness to join ${ }^{14}$ and willingness to pay for such health insurance. ${ }^{15}$ Also, it has been reported that MIUs usually cover a partial benefit package and that clients are sometimes involved in defining benefit packages. ${ }^{16}$ Systematizing this practice necessitated the development and testing of a method to elicit clients' preferred priorities, ${ }^{17}$ and to assess the judiciousness of clients' choices. ${ }^{18}$ A fuller summary of the accumulated knowledge on MIUs would take too much space and would be beyond the scope of this paper; therefore, the purpose of this brief review is simply to point interested readers in the direction where they can find more information on this nascent form of health insurance.

Other recent developments regarding micro insurance include public-private partnership in commissioning a series of field case studies on good and bad microinsurance practices, holding an international conference in October 2005 on this topic, and the publication of a comprehensive book that summarizes the knowledge gained through the previous two activities. ${ }^{19}$ This book includes a chapter on the definition of micro insurance, written by Craig Churchill; according to him, MIUs are financial arrangements to protect low-income people against specific perils, covering a variety of different risks (e.g., illness, death, property loss, etc) in exchange for regular premium payments that are usually small and proportionate to the likelihood and cost of the risk involved. ${ }^{20}$ Another chapter provides an analysis of the distinct organizational models of MIUs. ${ }^{21}$ Considering that many MIUs deal with a wide range of heads-of-damage, and operate either as agents or as friendly societies or as mutuals, we wish to limit our reference in this paper to MIUs that cover health risks and that underwrite the risk at least in part, that is, MIUs that can be compared to

${ }^{4}$ ILO (2002a, b)

${ }^{5}$ ILO/STEP (2005a)

${ }^{6}$ ILO/STEP (2005b)

${ }^{7}$ ILO/STEP (2003a)

${ }^{8}$ ILO/STEP (2003b)

${ }^{9}$ ILO/STEP (2003c)

${ }^{10}$ Devadasan et al. (2006)

${ }^{11}$ Dror et al. (2005a)

${ }^{12}$ Dror et al. (2005b)

13 Preker et al. (2002)

14 Zhang et al. (2006)

${ }^{15}$ Habbani et al. (2006); Dong et al. (2005); Dror et al. (2006c)

${ }^{16}$ Miller Franco et al. (2004); Preker et al. (2002); Danis et al. (2004); Loewenson (1999)

17 Danis et al. (June 2006)

18 Dror et al. (2006a)

${ }^{19}$ Churchill (2006a)

${ }^{20}$ Churchill (2006b)

${ }^{21}$ Radermacher and Dror (2006) 
mutual insurers (regardless of whether they are formally licensed as cooperative insurers). Finally, it is noted that the International Association of Insurance Supervisors (IAIS) and the World Bank's Consultative Group to Assist the Poorest (CGAP) have recently embarked on drafting an Issue Paper on the Regulation and Supervision of Microinsurance, which could offer a framework for possible regulatory provisions for the operation of micro insurance. The aggregate impact of growing outreach, better research, and new thinking on regulation of this form of insurance clearly suggests that micro insurance is on the radar screen of those wishing to see the development of insurance penetration into the informal economy and among low-networth persons.

Yet there is painfully little literature on how MIUs perform in terms of insurance economics. Bonnevay et al. ${ }^{22}$ examined the theoretical basis for the long-term viability of MIUs and concluded that MIUs need reinsurance and that reinsurance of MIUs can work. Feeley et al. $^{23}$ wrote an evaluation of the regulatory framework for providing reinsurance to MIUs, and Fairbank ${ }^{24}$ wrote an organizational evaluation of Bonnevay's mathematical elaboration, suggesting that the very small client-base of MIUs explained why no reinsurer accepts the risks of MIUs today. We could not find any other economic analysis of the insurance function of MIUs (except an earlier version of this paper). This article takes the economic analysis beyond the theoretical study of Bonnevay et al. while retaining the essential economic assumption that MIUs operate as stand-alone entities. The focus of this article is on the following economic evaluation of MIUs: (i) an estimate of their capital needs; (ii) quantitative estimates of the impact of group size on capital requirements, relative to overall cost of the claim load; and (iii) a comparison of the cost of retaining capital with the cost of a reinsurance premium.

\section{Data and methods employed in this study}

\section{Database}

The objective of the exercise here is to compare the capital requirements that apply to insurers with different sizes of insureds, all other things being equal. Ideally, one would wish to use actual data of sufficient size and quality emanating from MIUs. Unfortunately, we were unable to analyse actual claims data of MIUs operating in the field, as the number of MIUs and their sizes in reality are much smaller than the scope of this simulation. Additionally, we have no valid basis to assume uniform rates of mortality, morbidity and duration of illnesses or unit- and claims costs for all MIUs. Therefore, using actual data of MIUs could raise questions whether we are comparing equal with equal, a condition that is required for an analysis of the impact of group size under the condition of ceteris paribus. Bonnevay et al. (see footnote 22) used as source for their simulations a dataset obtained through a random-number generator assuming that the incidence is distributed according to Poisson distribution and the unit cost in $\chi^{2}$ distribution function. The difficulty with this option is

\footnotetext{
22 Bonnevay et al. (2002)

${ }^{23}$ Feeley et al. (2002)

${ }^{24}$ Fairbank (2003)
} 
that it would require postulating many complex assumptions about distributions and incidence of events and costs, as well as dependence or independence between events, if we would wish the artificial data to resemble real-life situations; and no matter how complex the assumptions, it would be impossible to verify the quality of fit-to-reality.

Fortunately, we have been able to access the 2001 data set of a large health insurer in Ireland, containing upward of 1.3 million insureds, which is sufficiently large, and for which practically all claims were settled ("the original data set"). We consider this data set to be robust because of its size and the stable nature of the claims profile experienced by this insurer. We thus performed the analysis by using an empirical distribution of health care expenditure of that health insurer in Ireland and broke up the large data source into many small "virtual MIUs", and looked at each as a stand-alone entity. Using this alternative obviated the need to make assumptions on the relationships between events or on the costs incurred, as these are inherent in the data set.

We wish to emphasize that we do not ignore the huge differences in health care settings, disease profiles and levels of claim control in low-income rural areas compared to conditions that prevail in Ireland. For one, we do not assert that the Irish data is indicative of insurance experience in low-income countries where MIUs operate. We state more on this in the section describing the limitations of the model. However, we think that the Irish dataset is superior to laboratory-generated data for the purpose of disaggregating a large pool of insureds into smaller units through repeated re-sampling without replacement (bootstrap) and counting the frequencies of excess loss for each smaller unit, because the sub-groups are perfectly comparable to each other in terms of morbidity, claim experience, unit costs and levels of claim control.

\section{Data yield}

We split the original data set into smaller groups; the number of the smaller groups was determined randomly. We obtained 535 "virtual MIUs". With the view to emulating the likely range of sizes of MIUs, ${ }^{25,26}$ we applied a decision rule that each group had to count no less than 200 and no more than 5,500 insureds; within this rule, the size of membership of each group was determined randomly, and was kept unchanged throughout the experiment.

\section{The modelling exercise (iterations)}

We ran over 1,000 iterations (1,005 to be precise) of the database; in each round, we assigned individuals randomly from the original data set to one of the virtual MIUs. For each individual that was assigned, we copied the total claims cost from the original

\footnotetext{
${ }^{25}$ With the notable exception of Yeshasvini Trust (see reference in footnote 26), a "micro" health insurance in Karnataka (India) that has upward of a million members, all other documented cases mention the size of MIUs to be a few hundred to a few thousand members. We are guided here by this range.

${ }^{26}$ Radermacher et al. (2005)
} 
The Geneva Papers on Risk and Insurance - Issues and Practice

744

Table 1 Data Yield (A breakdown of the number of virtual MIUs)

\begin{tabular}{lccc}
\hline Size of MIU (persons) & No. of MIUs & Iterations & Number of MIUs (all iterations) \\
\hline $200-1000$ & 95 & 1,005 & 95,475 \\
$1000-2000$ & 123 & 1,005 & 123,615 \\
$2000-3000$ & 121 & 1,005 & 121,605 \\
$3000-4000$ & 120 & 1,005 & 120,600 \\
$4000-5500$ & 76 & 1,005 & 76,380 \\
All & $\mathbf{5 3 5}$ & $\mathbf{1 , 0 0 5}$ & $\mathbf{5 3 7 , 6 7 5}$ \\
\hline
\end{tabular}

data set to the relevant virtual MIU for the entire year. As stated earlier, the number of virtual MIUs remained unchanged throughout the 1,005 iterations; and the number of individuals in each virtual MIU remained constant as well. In this way, we obtained a random and different composition of persons in each virtual MIU at each iteration, reflecting a distinctive membership structure by age, gender, health status and all other risk factors affecting the level of health care utilization. Consequently, by having run 1,005 iterations of the original data set to obtain 535 virtual MIUs in each run, the total data yield in this experiment has been 537,675 virtual MIUs. The breakdown of this number of virtual MIUs by membership size is shown in Table 1 .

\section{Assumptions}

\section{Income}

We assume that all virtual MIUs derive their income from premiums only. We further assume that the premiums are calculated in relation to the long-term average cost of claims, rather than relative to individual risk (risk rating) or to annual experience rating for each year separately (community rating). The proxy for the long-term average cost is the average community-rated premium for the original dataset (rather than an MIU-specific community or another rate). ${ }^{27} \mathrm{We}$ call this benchmark the "market average per-capita cost". This benchmark premium may be lower than the MIU-specific community rate.

\section{Cost experience of virtual MIUs}

The actual cost each virtual MIU must bear (in each of the 1,005 iterations) is the sum of the total cost of health care used by all members of each virtual MIU in each iteration, copied from the original data set. The cost experience of each MIU was then compared to the benchmark market average per-capita cost.

\section{Method of calculating capital requirements}

We assume that the original data set must have the capital to cover the aggregate loss experience in the given year. Similarly, each virtual MIU needs surplus capital to cover

\footnotetext{
${ }^{27}$ The pool-wide community rate acts as equalizer of some of the risk across the MIUs, and in reality a mechanism must be established for this equalization, which will reallocate amounts between MIUs and cover the possible difference between the sum of MIU-specific community rates and the pool-wide community rate.
} 
its accumulated losses. As the market average per-capita cost is assumed to be the sole source of income, we consider the shortfall in capital of a virtual MIU compared to that benchmark as the indicative measure for capital needs.

Incidences where the costs of virtual MIUs exceeded the benchmark were noted for all virtual MIUs in all iterations. With the exception of three of the 1,005 iterations, over 90 per cent of average claims for each MIU occur within \pm 25 per cent of the mean cost ${ }^{28}$ however, as expected, the distribution of these differences changed somewhat across iterations, and tails were skewed (meaning that the extreme situations occur more often than predicted by a perfectly normal distribution). We are interested here in the right side of the tail; the longer the tail, the greater the eventuality that claims exceeding the market average per-capita cost (outlier claims) could occur, and the greater the amount of capital the virtual MIUs need. Using the overall distribution of the deviations of costs from the benchmark, ${ }^{29}$ and applying an adjusted form of the statistical boot-strap method, ${ }^{30}$ we calculated the amount that needs to be added to the premiums to secure the solvency of each virtual MIU at a given level of confidence (this amount is equated here to loading for capital accumulation).

\section{Independence}

As each virtual MIU is defined by the number and characteristics of its "members" (which change from one iteration to another), we assume that the virtual MIUs are independent from each other, that is, no interactions or correlations between them exist. As we are using data of a real health insurer, we need not postulate any assumptions about the independence of cost-generating events or about possible correlations between different causes of morbidity. Possible correlations, if any, are already embedded in the claims data used. For the same reason we can also forego any assumption on the statistical distribution functions of the costs.

\section{Confidence levels ${ }^{31}$}

We look at confidence levels of 99.9, 99.5, 99.0 and 95.0 per cent.

${ }^{28}$ In the three cases 89 per cent of claims for each MIU were within this range.

${ }^{29}$ The difference between the mean claims cost of the single MIU and the market average per-capita cost, divided by the market average per capita cost.

${ }^{30}$ The method pioneered by Efron (1979) uses repeated samples as a basis for calculating the underlying statistical distribution of the random variable. Combined with this, the Law of Large Numbers postulates that when observations are independently and identically distributed, the sample statistics converge to the underlying population value as the number of iterations $n$ becomes "large" (Athreya (1983)). This method is described in more detail by Chernick (1999) and Green (1997).

31 The Confidence level is the probability value $(1-\alpha)$ associated with a confidence interval. It is often expressed as a percentage. Confidence intervals are usually calculated at 95 per cent, but one can produce 90, 99, 99.9 per cent (or whatever) confidence levels for the unknown parameter. For example, if $\alpha=0.05=5$ per cent, then the confidence level is 95 per cent $=(1-0.05)=0.95=95$ per cent. The interval gives an estimated range of values for an unknown parameter, calculated from a given set of sample data. If independent samples are taken repeatedly from the same population, and a confidence interval calculated for each sample, then a certain percentage of the intervals (confidence level) will include the unknown population parameter. 


\section{Findings}

The level of capital was calculated by comparing the difference in costs per insured in a single large pool of 1.3 million insureds with the same cost when the same persons are distributed randomly over 535 virtual MIUs of different sizes and at different confidence levels. In this exercise, both the overall size of the population of the original dataset and the number of virtual MIUs remained steady (with an average size of 2,426 individuals). In addition, we created 53 medium-sized virtual MIUs (each counting no less than 2,000 and no more than 55,000 insureds, that is, 10 times larger than the 535 virtual MIUs, with average size of 24,492 individuals), and 10 large virtual MIUs (each counting no less than 10,600 and no more than 291,500 insureds, with average size of 129,808 persons), also simulated 1005 times. The purpose of these very large virtual MIUs has been to enlarge the observations of the impact of different group sizes on capital requirements, in addition to the question of capital required by these virtual MIUs. Capital requirements are expressed as a percentage of the overall average cost. The results are presented in Table 2 .

As can be seen in Table 2, a higher confidence level is associated with a higher capital requirement. For example, a virtual MIU must load 44.5 per cent to its total annual cost in order to have sufficient funds to pay all its costs at 99.9 per cent of the cases, but only 37.1 per cent of annual costs at confidence level of 99.5 per cent, and only 23.7 per cent at confidence level of 95.0 per cent.

It is not surprising that a higher confidence level requires more capital (as it means less tolerance that virtual MIUs would go bankrupt). In this example, when confidence levels are lowered from 99.9 to 95.0 per cent, capital requirements drop very sharply, by almost 50 per cent. One might expect that the reduction in the probability of insolvency by a factor of 50 times would have a very significant effect, which would preclude a linear risk-return shape; and considering that in a normal distribution we would expect about 68.2 per cent of the observations to occur within one standard deviation, 95.4 per cent within two SD and 99.6 per cent of the occurrences within three SD of mean, the steep drop in capital requirement as the confidence level is lowered demonstrates a similar phenomenon. One could explain the sharp decline also in another way: the very rare cases are at the right tail of the distribution and thus the more costly ones. Therefore it costs so much more to ensure full financial cover for the most expensive 5 per cent of outliers. This finding could have important policy implications.

Table 2 also illustrates that at an identical confidence level, small groups must secure a much higher level of capital than large groups. For example, at confidence level of 99

Table 2 Capital requirements for different group sizes and at different confidence levels

\begin{tabular}{lccc}
\hline Number of virtual MIUs to which the sample was divided & 535 & 53 & 10 \\
Average number of insureds per virtual MIU & 2,426 & 24,492 & 129,808 \\
Mean variation from overall average cost & $0.03 \%$ & $0.00 \%$ & $0.00 \%$ \\
Standard deviation from average cost & $14.40 \%$ & $1.09 \%$ & $0.20 \%$ \\
Capital requirements at 99.9 per cent confidence level & $44.52 \%$ & $3.38 \%$ & $0.61 \%$ \\
Capital requirements at 99.5 per cent confidence level & $37.12 \%$ & $2.82 \%$ & $0.51 \%$ \\
Capital requirements at 99.0 per cent confidence level & $33.53 \%$ & $2.54 \%$ & $0.46 \%$ \\
Capital requirements at 95.0 per cent confidence level & $23.72 \%$ & $1.80 \%$ & $0.33 \%$ \\
\hline
\end{tabular}




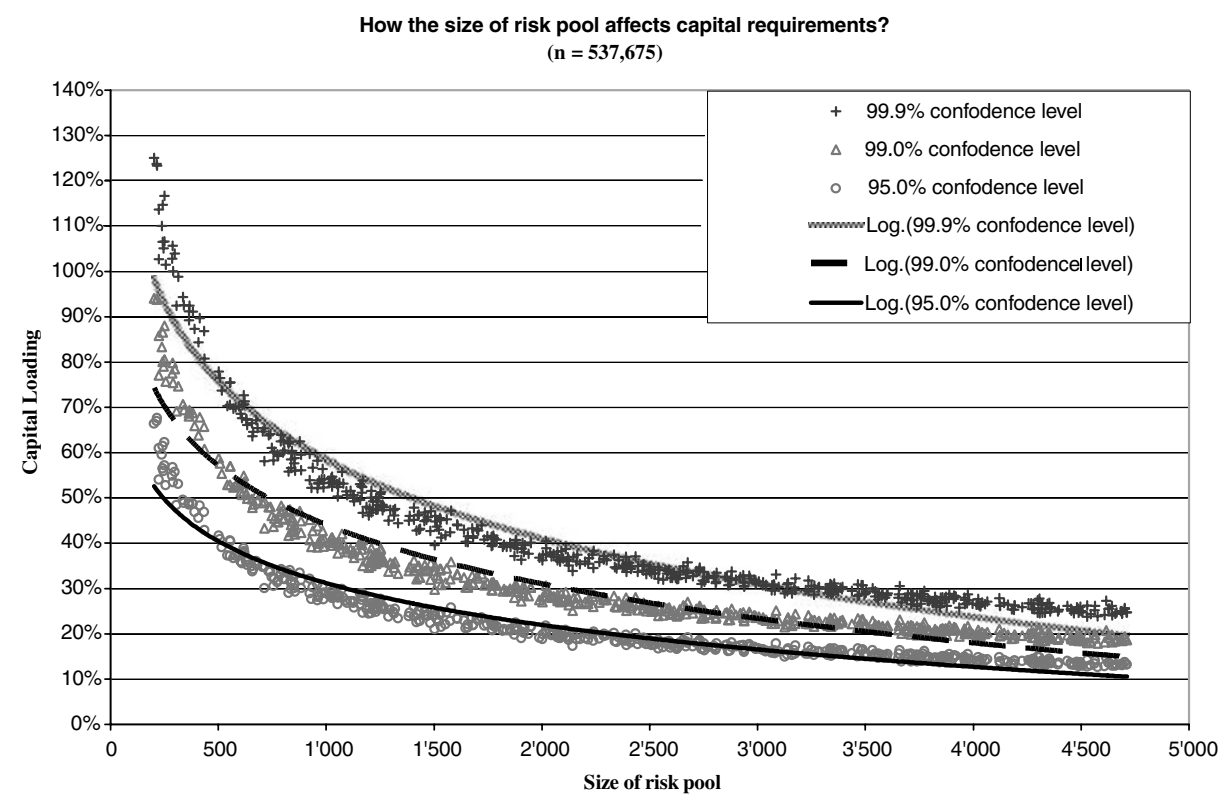

Figure 1. Capital loading and group size.

per cent, virtual MIUs with an average size of 2,426 members must load 33.5 per cent of annual cost to ensure adequate capital reserves, compared to $<0.5$ per cent for virtual MIUs with 129,808 insureds. This result shows the huge impact of increasing group size on reducing the standard deviation of the variation of the average cost of the virtual MIUs compared to the overall average cost of the pool of 1.3 million insureds. As we consider this variation to be a proxy measure for capital requirements, we conclude that group size has a determining influence on capital loading. We have also plotted the results for the entire dataset of 537,675 small virtual MIUs as an additional illustration of the relationship between group size and capital loading levels (Figure 1). This insight could also have policy repercussions.

\section{Capital requirements for smaller virtual MIUs (typical for the initial period of activity)}

We anticipate that when MIUs start operating, they are likely to induct few insureds (and, incidentally, fewer MIUs are likely to exist so the pool will also be smaller). We therefore estimate the capital required under the scenario that both the size of membership and the number of MIUs will increase gradually.

For this illustration, we filtered from the original dataset the virtual MIUs that were randomly assigned small group sizes: in the first year, we looked at the data of the 95 virtual MIUs with up to 1,000 insureds; in year 2, we looked at the data of the 218 virtual MIUs with up to 2,000 insureds; in year 3, we looked at the data of the 339 virtual MIUs with up to 3,000 insureds; in year 4, we looked at the data of the 459 virtual MIUs with up to 4,000 insureds; and in year 5, we looked at all the 535 MIUs, each with up to 5,500 insureds. The calculated estimates, at the same 
confidence levels that were used before, are given in Table 3 . The bold numbers in Table 3 are identical to data already shown in Table 2, reproduced here for ease of comparison of the smaller virtual MIUs to the 535 virtual MIUs.

Table 3 provides data that amplifies the insight that capital requirements are considerably higher for virtual MIUs with fewer insureds, and that capital requirements drop also when the confidence level is lowered. For example, at confidence level of 99.9 per cent, capital loading above average costs is 75.3 per cent when average group size is under 1,000 members and drops to 44.5 per cent when average group size increases to 5,500. And when the confidence level is relaxed to 95 per cent, the corresponding loading factors drop to 40.0 and 23.7 per cent, respectively.

\section{Consequences of retaining insufficient capital}

MIUs that retain low or no capital reserves run the risk of insolvency. An estimate of this risk is presented in Tables 4 and 5. Table 4 contains the expected solvency of the 535 virtual MIUs in the original dataset; Table 5 presents the expected insolvency rates for smaller virtual MIUs.

The bold-highlighted figures in Table 4 are identical to those shown in Table 2, and are repeated here for ease of reference. This table shows that if the average capital retained by the simulated 535 virtual MIUs is lower than the required 23.7 per cent, the expected probability of insolvencies grows quite dramatically. And, as could be expected, it would be even higher when smaller virtual MIUs fail to keep adequate capital levels. These calculations are presented in Table 5.

Table 5 provides the demonstration that average group size also influences the risk of insolvency due to insufficient capital. For example, when capital retention is 20 per cent, the larger groups (average group size 2,426) have 8.3 per cent risk of insolvency, whereas smaller virtual MIUs (with average membership of 620) incur 21.6 per cent risk of insolvency. Interestingly, the gap between larger and smaller groups diminishes as capital inadequacy becomes more pronounced, and disappears altogether in the extreme case that the virtual MIUs keep no capital at all. In such situation, all virtual MIUs run an identical risk of insolvency of 50 per cent, regardless of their size. It should be noted that the risk of insolvency increases over time as well: even if an MIU

Table 3 Capital requirements for smaller MIUs with fewer insureds

\begin{tabular}{lccccc}
\hline Year & 1 & 2 & 3 & 4 & 5 \\
\hline Number of virtual MIUs in the pool & 95 & 218 & 339 & 459 & 535 \\
Number of insureds per virtual MIU & $\leqslant 1,000$ & $\leqslant 2,000$ & $\leqslant 3,000$ & $\leqslant 4,000$ & $\leqslant 5,500$ \\
Avg number of insureds per virtual MIU & 620 & 1,092 & 1,594 & 2,103 & 2,426 \\
Mean variation from overall average cost & $0.16 \%$ & $0.11 \%$ & $0.06 \%$ & $0.05 \%$ & $0.00 \%$ \\
Standard deviation from average cost & $24.20 \%$ & $19.30 \%$ & $16.80 \%$ & $15.20 \%$ & $14.40 \%$ \\
Capital requirements at 99.9 per cent confidence level & $75.30 \%$ & $59.90 \%$ & $52.00 \%$ & $47.00 \%$ & $44.52 \%$ \\
Capital requirements at 99.5 per cent confidence level & $62.60 \%$ & $49.90 \%$ & $43.40 \%$ & $39.20 \%$ & $37.12 \%$ \\
Capital requirements at 99.0 per cent confidence level & $56.60 \%$ & $45.10 \%$ & $39.20 \%$ & $35.30 \%$ & $33.53 \%$ \\
Capital requirements at 95.0 per cent confidence level & $40.00 \%$ & $31.90 \%$ & $27.70 \%$ & $25.00 \%$ & $23.72 \%$ \\
\hline
\end{tabular}


Table 4 Expected insolvency rates at various levels of capital shortage

\begin{tabular}{lc}
\hline $\begin{array}{c}\text { Margin of retained capital (above } \\
\text { average market cost) }\end{array}$ & $\begin{array}{c}\text { Expected proportion of all schemes } \\
\text { becoming insolvent }\end{array}$ \\
\hline $23.72 \%$ & $5.0 \%$ \\
$20 \%$ & $8.3 \%$ \\
$10 \%$ & $24.5 \%$ \\
$5 \%$ & $36.5 \%$ \\
$1 \%$ & $47.3 \%$ \\
$0 \%$ & $50.0 \%$ \\
\hline
\end{tabular}

Table 5 Expected insolvency rates of small MIUs

\begin{tabular}{|c|c|c|c|c|c|c|c|}
\hline \multirow[t]{3}{*}{ MIUs in simulation } & \multirow[t]{3}{*}{ I Average MIU Size } & \multirow[t]{3}{*}{ Insureds } & \multicolumn{5}{|c|}{ Retained Capital } \\
\hline & & & $0 \%$ & $1 \%$ & $5 \%$ & $10 \%$ & $20 \%$ \\
\hline & & & \multicolumn{5}{|c|}{ Expected proportion of all schemes becoming insolvent } \\
\hline 95 & 620 & $\leqslant 1,000$ & $50.00 \%$ & $48.60 \%$ & $42.10 \%$ & $34.20 \%$ & $21.60 \%$ \\
\hline 218 & 1,092 & $\leqslant 2,000$ & $50.00 \%$ & $48.10 \%$ & $40.00 \%$ & $30.40 \%$ & $15.20 \%$ \\
\hline 339 & 1,594 & $\leqslant 3,000$ & $50.00 \%$ & $47.80 \%$ & $38.20 \%$ & $27.40 \%$ & $11.80 \%$ \\
\hline 459 & 2,103 & $\leqslant 4,000$ & $50.00 \%$ & $47.50 \%$ & $37.30 \%$ & $25.60 \%$ & $9.50 \%$ \\
\hline 535 & 2,426 & $\leqslant 5,500$ & $50.00 \%$ & $47.30 \%$ & $36.50 \%$ & $24.50 \%$ & $8.30 \%$ \\
\hline
\end{tabular}

with insufficient capital survives the first year, its aggregated probability to survive two years is lower, three years even lower, etc.

Before concluding this section we wish to remind that this analysis is expressly limited to estimating capital loading in respect of underwriting risks, that is, the capital required to cover outlier cost of benefits above the expected average per insured. We are aware that the prevailing practice in the insurance industry is to base the calculations on additional components of operational risk. More on this point is explained in the section that deals with the limitations of the model.

\section{Discussion of the findings}

\section{Micro health insurance units need capital}

It was stated earlier that this paper focuses on MIUs that underwrite health risks. MIUs that underwrite risk fill the institutional role of providing insurance in surroundings where affordable and pertinent insurance products are usually hard to get. Although the business process and the value chain of MIUs differ from those of commercial insurers, some fundamentals are nevertheless similar. One of these fundamental essentials is the ability of MIUs to pay all underwritten claims at all times. Capital loading is one way to secure that such an engagement is kept. Insurers collect premiums that should normally pay for their customers' losses in full. This 
implies that when insured losses exceed premium income, insurers must pay for losses out of their own capital. Therefore, insurers need surplus capital as a buffer against insolvency when they experience outlier costs. The higher the uncertainty about the characteristics of the covered risk, the more difficult it is to calculate premiums accurately. In these circumstances, insurers usually increase the capital loading to reduce their risks. The theoretical explanation for capital needs is that outlier costs can occur due to statistical fluctuations in the number or in the cost of claims or both ("underwriting risk"), but also due to other reasons. Incidentally, the same logic applies to operational risks, which are however outside the focus of this article. ${ }^{32}$

It has been shown that MIUs operating with insufficient or no capital are exposed to a considerable risk of insolvency. We must recognize that adding a capital loading to premiums also represents a risk that clients might consider the premiums unaffordable or unfairly high. However, we feel that insolvency is the bigger of the two risks, because default on benefit payment is a bigger dampener of trust, and without trust there is no insurance. We therefore conclude that MIUs need capital (or foolproof capital relief, e.g., external deficit guarantees).

\section{Impact of group size on capital requirement}

What we have seen in this study, based on the observed benefit cost of 537,675 virtual MIUs, leads us to say that capital loading is very sensitive to group size, and causes considerable increase in the premium, observed in particular for small group-sizes that are typical of MIUs. The observed values of capital loading range from a low of 23.7 per cent (at confidence level of 95 per cent and average group size 2,426 insureds) to a high of 75.3 per cent (at confidence level of 99.9 per cent and average group size of 620 insureds) (see Tables 3 and 5).

An earlier analysis of the impact of group size ${ }^{33}$ linked the phenomenon to two statistical characteristics: first, at an identical risk, small groups have a wider distribution, and thus a higher likelihood of outlier claims. Secondly, when the probability drops, small groups benefit less from that drop, because of the larger variance. That study (based on theoretical assumptions of risk distributions of two virtual MIUs, one of 100 and the other of 1,000 members) concluded that a major source of uncertainty of MIUs was their small group size. This study suggests that the impact of group size does not disappear even when groups number about 25,000 insureds, or 25 times larger than in the theoretical analysis. The relevant data is shown in Table 2: a tenfold increase from 2,426 to 24,492 insureds resulted in the lowering of the standard deviation from 14.1 to 1.1 per cent but this was still much higher than 0.2 per cent, which was registered for the virtual MIU with 129,808 members. This insight is new, and is probably linked to a lower decline in the variance due to unit cost than to the variance due to the incidence.

\footnotetext{
${ }^{32}$ We refer here to "operational risks" but shall not deal with these here, other than to point out that there is no uniform and generally accepted definition of operational risk. Incidentally, there is much debate on how this risk can be quantified and whether it should be counted in the risk-based capital requirements of the insurer.

${ }^{33}$ Dror (2001); Dror and Preker (2002).
} 


\section{Impact of confidence interval}

The second important insight gained from this study is that the impact of changes in confidence levels is weaker than the impact of changes in the number of insureds on capital loading levels. For example, an increase in the number of insureds from 2,426 to 24,492 reduced capital requirement from 44.5 to 3.4 per cent (about 13-fold), whereas a decrease of the confidence interval from 99.9 to 95 per cent brought about a reduction in capital requirements from 44.5 to 23.7 per cent (less than two-fold) (Table 2).

\section{Impact of insufficient reserving}

When capital reserves are lower than required the risk of insolvency increases rapidly. Considering that small MIUs must load higher levels, they have a more difficult job to get clients to pay a loading factor of, for example, 25 per cent than 30 or 40 per cent. Consequently, small MIUs are more likely to be insufficiently capitalized, and therefore also more exposed to the risk of insolvency and bankruptcy. It is of course self-explanatory that when the virtual MIUs do not retain any capital at all, their group size no longer influences their risk of insolvency, which is a uniform 50 per cent.

\section{Alternatives to maintaining capital}

We refrain from discussing the desirable but hypothetical option of government funding of social health insurance, which would obviate the phenomenon of MIUs in lowincome countries. We focus on the reality of health financing in low-income countries, which includes MIUs; and we are interested to explore what can be done to enable them to operate on a sustainable basis, which is also in line with tried-and-tested mechanisms in use by the insurance industry. Two options seem the most likely: reinsurance and partial subsidization. Needless to say, these two options are not mutually exclusive. However, for the sake of clarity of the discussion, we treat each separately.

\section{Reinsurance}

The original purpose of reinsurance is to enable primary insurers to limit their exposure to the (more affordable) average cost of the underwritten risk, while transferring to another risk-carrier the costs linked to unexpected changes in the portfolio or business environment. This relationship is based on two fundamental processes: (i) Reinsurance enlarges the pool of insureds captured by its clients, the primary insurers, for better diversification. This upward move along the insurance "production chain" (which looks like an inverted pyramid) translates to a higher absolute claim-load and a smaller difference between actual and expected results. (ii) Reinsurance simplifies primary insurers' access to reinsurers' larger supply of capital and information. Reinsurers may actually be exposed to more outlier risks than primary insurers, but can nevertheless improve the value chain because they can enjoy lower cost of capital through better leveraging; one very tangible aspect is that reinsurers are required to meet lower/different levels of solvency compared to primary insurers. Therefore, they can underwrite more risk for every dollar of capital/surplus. ${ }^{34}$ 
Secondly, reinsurers have a unique inside view of the insurance industry, particularly in markets where they interact with a large number of primary insurers. Therefore, they can share with clients an understanding of how best to address underwriting challenges and management concerns about expanding (or reducing) their existing product lines. This expertise is valuable for primary insurers who are particularly exposed to the risk of error in estimating the underwritten average risk or the cost of claims of a new product ("innovation error").

How prevalent is reinsurance? Considering that the global insurance market is largely concentrated in very few rich countries, ${ }^{35}$ and bearing in mind that only one lower-middle income country has high insurance penetration ${ }^{36}$ but not a single lowincome country, we can well assume that reinsurers are not all that familiar with the context of MIUs. There are of course reinsurers in several low-income countries, such as General Insurance Company (GIC) in India, which serve their commercial insurance companies, and which sometimes even enjoy monopoly or quasi-monopoly status. However, these country-specific reinsurers have very little exposure to reinsurance of health insurance. Hence, the expertise in health reinsurance is relatively modest, their acquaintance with risk profiles of MIUs is rather cursory, and the offer of reinsurance is very rare indeed.

MIUs have limited experience in underwriting risk professionally, and virtually no experience with ceding risks to reinsurance. In fact, two obstacles stand in the way of exploiting this option: the legal/regulatory barrier, and the doubts about clear win-win relations. The regulatory obstacle consists of requiring reinsurers to do business only with registered/licensed insurers; many MIUs are not registered as insurers, would probably be unable to qualify for such license due to various financial and formal barriers to entry. For instance, in India, where quite a number of MIUs operate, the regulatory requirement for insurance license includes depositing Rs 1 billion ( $\sim$ US\$ 22 million), an amount that is prohibitive, disproportional to the risk that the MIU would underwrite, and which excludes any MIU from qualifying for formal recognition. Consequently, neither side can negotiate or sign treaties. Secondly, in most low-income countries, just as most poor people cannot buy insurance, MIUs cannot buy reinsurance. This has been explained by the Chairman of the Supervisory Board of Munich Re, Dr. Hans-Jürgen Schinzler, in his address to the Microinsurance Conference in October 2005: "Premium income is low, administrative costs are relatively high, and infrastructure for insurance is lacking; that's why commercial insurers have not taken more interest in this market". ${ }^{37}$ But even if the reinsurers would decide to show more interest in the low-income market, MIUs would also need

\footnotetext{
${ }^{34}$ Capital/Surplus=Admissible Assets - Liabilities

${ }^{35}$ In 2005, 85 per cent of global premium volume was concluded in only 10 countries (U.S.A., Japan, U.K., Germany, France, Italy, South Korea, Canada, Spain and The Netherlands) of which five countries captured almost 75 per cent of global insurance premiums (U.S.A., Japan, U.K., Germany, France). Source: Swiss Re (2006).

${ }^{36}$ The notable exception is South Africa, a middle-income country, which has the highest rate of premiums as percentage of GDP in the world.

${ }^{37}$ Churchill et al. (2006)
} 
to be convinced that they can gain from ceding the major part of their risks to reinsurance. It is not quite clear who should provide the technical support for such a development. The insurance industry seems in unison that cooperation with MIUs will occur only when reinsurers can earn a profit from it; and most MIUs find it difficult to understand why their poor clients should add to the profits of reinsurers that are much wealthier than the clientele of MIUs. For the time-being, neither governments nor development agencies have agreed to facilitate the development of win-win relations. The purpose of this paper is to show that there is substantive basis for doing so. The following section has more on this.

\section{Government subsidies}

It is taken as a given here that subsidies are an effective tool in directing public financing. There is more experience with subsidizing access to health care, but some proposals have been formulated to subsidize access to health insurance. For instance, the Commission on Macroeconomics and Health (in 2001) suggested "to offer local communities an incentive scheme, in which each $\$ 1$ that the community raises for prepaid health coverage would be augmented, at some rate of co-financing, by the national government (backed by donor assistance)". 38

This proposal to subsidize premiums would probably be complicated to implement due to the known difficulties in efficient targeting and controls against fraud. The analysis of capital loading opens up an alternative route for subsidization of health insurance: reducing the capital loading payable by insureds. This subsidy can be implemented for MIUs, which in any case operate in low-income and rural subgroups, and which are unlikely to induct persons who live far away from their centre of activity or earn much higher income. The internal logic of why governments should subsidize the equivalent of capital loading resides in taking a risk-equalizing measure that puts MIUs at par with larger groups in terms of financial solvency. Stated differently, if the government had a single (national) pool, its sheer size would have reduced the rate of capital loading; MIUs offering health insurance in lieu of a national social health insurance should not be exposed to higher vulnerability due to small group size, and their members, who are mostly low-net-worth, should not have to subsidize the cost of government inaction in this domain. In fact, government funding of the capital loading would bring the premium closer to the more affordable cost of pure risk, and this subsidy would be available only to those who agree to pay the (lower) premium. As the insureds would be unable to manipulate this capital loading or convert it into an income-related subsidy in the form of a voucher, this subsidy would be much easier and much cheaper to administer. The cost of capital loading would also compare very favourably for governments with the cost of delivering even a modest form of health insurance, because the cost of the loading is in all cases lower than the total amount of the premium. A practical way of implementing this form of subsidization would be through a reinsurer, namely through the affiliation of MIUs to a designated reinsurer that would offer reinsurance (e.g., stop loss or excess loss) at concessionary rates that reflect no or minimal capital loading.

\footnotetext{
${ }^{38}$ Sachs (2001, p. 60).
} 
The authors are aware that such a proposal has not yet been implemented anywhere. However, the idea of tying resource generation (by collecting a premium) to partial subsidization (by reducing component costs of the premium) offers a strong internal logic, coupled with lower public expenses, which nevertheless offer an improvement over the prevalent situation as it is known today.

This logic suggests that governments should be keen to support links between MIUs and a reinsurance facility, either by creating such facility directly or by enabling a nongovernmental social reinsurance to function. And one way to encourage such development is through subsidies. At least four reasons justify using government subsidies to reduce MIUs' reinsurance premiums: (i) as discussed earlier in this paper, the cost of the risk diminishes when the group is larger. The more MIUs join the reinsurance pool, the larger the overall group size, and the lower the community-rated reinsurance premium payable. All MIUs that participate in the reinsurance pool will capture sizeable savings compared to scheme-specific community-rated premium. However, no MIU would accept to absorb the cost of covering the risk of other MIUs. Therefore, the pooling arrangement can work if the difference between the pool-wide community rate and the MIU-specific risk rate is subsidized. The subsidy amount will in fact ensure that more risky and smaller MIUs will de facto enjoy a higher subsidy, and this targeting is very efficient because it does not require any additional administrative adjustment to base the subsidy on the inherent characteristics of reinsured health risk. (ii) One way of reducing the reinsurance premium and the contribution of the MIU is to reduce to zero the loading for capital requirements plus interest. This can be done if the necessary capital is supplied from another source, either as an upfront cash payment or by way of concessionary drawing rights in case of need. This subsidy can be limited in time to the first few years of operation of the MIU and the social reinsurer. (iii) MIUs have no experience with reinsurance, and the higher the reinsurance premium, the more likely their reluctance to pay it. Yet MIUs are most vulnerable financially precisely in the first few years, when they need reinsurance most, both for surplus relief and for technical assistance. A subsidy can reduce their status-quo bias. (iv) One of the arguments against supporting small MIUs is their inadequate administrative capacity. MIUs need capacity building and technical assistance, which they cannot pay for but which can be cheaper and more effective when provided by the reinsurance. This support is customary in the reinsurance industry, because it is not only cost-effective but enhances adherence to the industry rules on reporting and audit. The classical sharing of responsibilities entrusts frontoffice activities with the MIU (to capture their relative advantage in low-cost collection of contributions and social pressure to reduce free-riding), and back-office functions with the reinsurer in a pool-wide service centre (to process claims, analyse costs for actuarial, costing and product development purposes, negotiate with providers of health care, etc).

In closing, one should recall that there are a few examples of governments' role in support of the development of insurance through subsidies. For example, in Ghana the subsidy covers part of the health insurance premium, ${ }^{39}$ in Mexico, the government

${ }^{39}$ Atim et al. (2001) 
subsidizes part of the reinsurance premium of crop reinsurance (Agroasemex) ${ }^{40}$ in Turkey the government has created a reinsurance facility for earthquake risks. ${ }^{41}$ This list of examples is by no means exhaustive. And there are other measures that could be suitable, for example, guaranteeing drawing rights in case of catastrophic exposure.

\section{Tradeoff between reinsurance and accumulating capital}

Reinsurance is an alternative to holding contingency reserves (capital), and its cost is easily measured by the premium payable. All other things being equal, if the two alternatives are equal, they should be interchangeable. However, considering that capital markets are imperfect and that there is less than perfect information about the underlying risk of each insurer, the monetary cost of both options is unlikely to be equal. ${ }^{42}$ In addition, the reinsurance premium is calculated differently according to whether the reinsurance contract is proportional or non-proportional. For proportional reinsurance contacts, the larger the "ceding commission" the insurer receives from the reinsurer, the cheaper the net reinsurance premium. For non-proportional reinsurance contracts, pricing is based on the reinsurer's estimate of expected underlying losses, plus loading for administration costs and profit. One of the key questions is how the cost of reinsurance compares with that of retaining reserves.

As we cannot model the exact levels of reinsurance premiums in the way we have done for capital loading, we resort to the only model that we have found in the literature, the Social Re model, which claims that the minimum reinsurance premium is equal to half the standard deviation of the average cost of stand-alone MIUs (see footnote 30). Taking the values of the standard deviation given in Table 2, one can see that the premium would be lower than the loading for capital in all cases reviewed. However, it should be recalled also that at that premium level, the reinsurer can survive only if 20 MIUs or more are reinsured after five years. The numbers are shown in Table 6. Of course these numbers are merely indicative, and in reality it would be necessary to base the premium on the value of the standard deviation applying to each MIU specifically. But, as illustrated in Table 6, the gap between capital loading and reinsurance premium is so large that a small margin of error (due to the possible difference between average value of the SD and the specific value) does not fundamentally alter the conclusion.

The main insight is that the cost of reinsurance is much lower than the minimum capital needed to assure the solvency of MIUs for all group sizes. As a reminder, Table 2 shows that capital loading will be only 0.33 per cent when the size of the insured population reaches 129,808 clients at 95 per cent confidence level. Needless to say, this extremely large size is irrelevant as a comparison for most MIUs, and the only lesson one can draw from this information is that subsidizing the reinsurance premium can be done by comparison to a notional large group that would be akin to the pool of

\footnotetext{
${ }^{40}$ World Bank Institute (2004); AGROAsemex (2006)

${ }^{41}$ Gurenko (2000); Selamet (nd)

${ }^{42}$ In fact given the operational risk associated with MIUs the cost of acquisition of external capital may be prohibitive.
} 
The Geneva Papers on Risk and Insurance - Issues and Practice

756

Table 6 Comparison between reinsurance premiums and capital loading

\begin{tabular}{lccc}
\hline Size of MIUS & $\begin{array}{c}\text { Standard deviation } \\
\text { from average cost }(\%)\end{array}$ & $\begin{array}{c}\text { Estimated reinsurance premium } \\
\text { under the Social Re model (\%) }\end{array}$ & $\begin{array}{c}\text { Capital loading } \\
\text { (at 95\% confidence) }\end{array}(\%)$ \\
\hline$\leqslant 5,500$ & 14.40 & 7.20 & 23.70 \\
$\leqslant 4,000$ & 19.30 & 9.65 & 25.00 \\
$\leqslant 3,000$ & 16.80 & 8.40 & 27.70 \\
$\leqslant 2,000$ & 19.30 & 9.65 & 31.90 \\
$\leqslant 1,000$ & 24.20 & 12.10 & 40.00 \\
\hline
\end{tabular}

a universal health insurance. Hence the extra large group of insureds shown in Table 2 could be a relevant benchmark.

Similarly, there could be an option to subsidize the difference in capital loading due to the application of a higher versus a lower confidence level. The same logic applies: all parties have an interest that MIUs should remain solvent. The cost of applying the difference is relatively low, and this subsidy cannot be subject to the habitual concerns of abuse, free riding or misappropriation, in so far as the reduction in the loading translates into a reduced premium, and this reduction can be captured only by those who agree to pay the premium but by nobody else.

\section{Limitations of the model}

This paper focuses on the risk of random clustering of cost-generating events, which is greatly affected by the claim-load, which in turn is directly associated with membership size. The exposure to these issues is one of the defining characteristics of MIUs.

The novelty of this study resides in using an actual database that reflects real health events, real costs, real statistical distributions and the real correlations between events. However, all these "real" components relate to the reality of Ireland, which is quite different from the reality of MIUs. We nevertheless used this database because the prospect of using real empirical data of MIUs, desirable as it is, is unrealistic for the time being due to lack of sufficient data and lack of standardization of definitions of relevant parameters. We felt that the Irish data set is superior to an artificial database obtained through a random number generator, plus a series of assumptions about distributions and interdependencies. We recognize that the model we present should not be construed to suggest that we present an accurate approximation of the costs of real MIUs. The real costs could be calculated with exact information on the relevant epidemiological situations, morbidity, definitions of benefits covered by insurance and the costs of care. In particular, the incidence of infectious diseases is higher in most low-income countries, and can be much more prone to fluctuations than in Ireland, but by no means uniform for all low-income countries. Secondly, statistical fluctuations are strongly dependent on the actual claim load, which is smaller in MIUs because of the compound effect of small group size and of the limited benefit package. That said, it is also clear that the trends affecting capital loading will be the same in Ireland and in areas where MIUs operate, even if absolute values differ. 
Specifically, a steep increase in capital loading can be expected when the group size decreases or when the confidence levels are increased.

Hence, this exercise is useful in terms of weighing economic alternatives of loading a capital factor to premiums or obtaining capital through reinsurance. The exact details will vary from only one MIU to another, relative to the specific risk exposure and the specific size and benefit package it offers.

In addition, we have dealt here only with capital loading within the definition given in this article. We specifically excluded additional loading related to operational risk, because its definition is not uniform even in the countries with high insurance activity.

While we recognize that group size is somehow related to topics such as propensity to join MIUs and willingness to pay, we formulate no assumptions on these issues because they are beyond the topic at hand. Nor do we deal with the difference in adverse selection or moral hazard on claim loads, because we used a dataset that already reflected the possible impact of these elements and did not require these assumptions for a relevant simulation exercise.

Finally, this simulation looked at a single year of operation. Were it not for logistical limitations, we would have liked to run multi-year results, notably in order to measure the effect of a longer time-series on capital requirements. That said, the size of the data being so large, it is unlikely that the results would change considerably from year to year.

\section{Conclusions}

This article set out to examine capital needs of "micro health insurance units" to ensure financial sustainability, and examine alternatives to satisfy these needs.

The detailed analysis of the impact of group size on capital needs of MIUs suggests that for an identical risk-exposure and an identical premium, MIUs may go bankrupt when larger groups will not. This quantitative illustration is extremely important for two reasons:

- First, it demonstrates that the poor are acting logically in refusing insurance that offers them lower financial protection for the same price that ensures higher financial protection to other insureds. Some would argue that the poor should be allowed to pay a lower premium, reflecting their lower ability to pay. But even those who reject this approach and plead for equal cost for the same level of riskmitigation must surely agree that it is unreasonable to expect the poor to pay a higher premium for an identical insurance product, emanating from a higher capital loading due to smaller group size. This illustration of the premium bias suggests that the market alone does not offer an automatic corrective measure; thus, insurance regulators would have a role to play in ensuring fair pricing that would not disadvantage clients of MIUs.

- Secondly, this is the first illustration of inherent reasons why MIUs must break away from stand-alone operations if they are to keep the cost of transfer of risk at affordable levels. The cost of transferring risk is linked to the size of the pool, and conceptually different from the cost of diversification. 
The analysis has shown that governments have many options to correct the premium bias caused by the higher capital requirement that MIUs must meet. Some of the options would be to subsidize the difference in capital loading that is directly related to small group size, by applying the capital loading rate that would apply to a large (national) group rather than the higher rate applicable to smaller MIUs. Governments could also create a facility that would allow MIUs to draw loans to meet their capitalization requirements in bad years. Additionally, governments could subsidize the difference in the cost of applying a lower confidence level by offering insolvency protection at a higher confidence level. This is of course very similar to reinsurance.

It should be stressed that interventions aiming to correct the size-related premium bias of MIUs address the cost of risk transfer (from individuals to small groups and from small groups to larger ones) without influencing the cost of risk bearing (which relates to the pure risk component of the premium).

It has been shown that the solution of reinsurance is cheaper capital loading (by reference to a model that provided a generalized formula for the cost of reinsurance relative to standard deviation). And it has been shown that MIUs need capital from inception. This leads us to suggest that MIUs cannot forego reinsurance from inception.

Reinsurance is a safer solution for governments compared to other alternatives, such as rolling out a modest version of social health insurance. The cost of universal cover under social health insurance is forbidding for most low-income countries, and can put governments under heavy pressure to constantly increase budget allocations as the needs grow. On the other hand, government facilitation of access to reinsurance, notably by subsidization of part of the reinsurance premium, mitigates governments' risk that they might have to pay without cap in cases where MIUs fail financially. By opening the tried-and-tested route that links MIUs to reinsurance, governments would have no more risk related to MIUs than they have in respect of any commercial insurer. The option of subsidizing the reinsurance premium would also be a more interesting alternative for governments than setting up social health insurance, because the subsidy of the reinsurance premium would be payable only in conjunction with premium payment by - and thus revenue generation from - the end beneficiaries of these subsidies. Such balance between revenues and payments would be very difficult to ensure through the alternative route of social insurance for the poor. Also, the accounting and accountability of flows of funds between insurer and reinsurer is much more stringent than can be expected in a publicly funded social health insurance.

In conclusion, the simulation exercise reported here shows that an increase in portfolio size increases diversification of risk (and vice versa); that without capital loading, the MIUs are exposed to an unacceptable risk of insolvency and bankruptcy; and that reinsurance is a cheaper substitute to holding solvency capital directly. These findings confirm that the basic principles underlying the success of insurance apply equally well to MIUs, which are in an embryonic form of underwriting risk and are usually composed of small groups. This confirmation is very important in determining the role of MIUs, and shows that if the barriers-to-ceding-risks to reinsurance that 
MIUs face today were removed, MIUs could offer a relevant and sustainable vehicle for extension of insurance penetration among low-income persons in low-income countries.

\section{References}

AGROAsemex (2006) 'Retrocession in AGROAsemex', http://www.agroasemex.gob.mx/english/acerca/ A4_01.html (accessed July 2006).

Athreya, K.B. (1983) 'Strong law for the bootstrap', Statistics and Probability Letters 1: 147-150.

Atim, C., Diop, F. and Bennett, S. (2005) Determinants of the Financial Stability of Mutual Health Organizations: A Study in the Thies Region of Senega, Bethesda, MD: The Partners for Health Reformplus Project, Abt Associates Inc.

Atim, C., Grey, S., Apoya, P., Anie, S. and Aikins, M. (2001) 'A survey of health financing schemes in Ghana', available online: http://www.phrplus.org/Pubs/Tech013_fin.pdf,accessed 15 July 2006.

Bonnevay, S., Dror, D.M., Duru, G. and Lamure, M. (2002) 'A model of microinsurance and reinsurance' (chapter 7), in D.M. Dror and A.S. Preker (eds) Social Reinsurance: A New Approach to Sustainable Community Health Financing, Washington: World Bank \& ILO, pp. 153-186.

Burdine, J.N., Felix, M.R.J., Wallerstein, N., Abel, A.L., Wiltraut, C.J., Musselman, Y.J. and Stidley, C. (1999) 'Measurement of social capital', Annals of the New York Academy of Sciences 896(1): 393.

Chernick, M. (1999) Bootstrap Method: A Practitioner's Guide, Hoboken, NJ: Wiley \& Sons (Wiley Series in Prob. \& Statistics).

Churchill, C. (ed) (2006a) Protecting the Poor: A Microinsurance Compendium, Geneva: ILO.

Churchill, C. (2006b) 'What is insurance for the poor?' (Chapter 1.1), in C. Chuchill (ed) Protecting the Poor: A Microinsurance Compendium, Geneva: ILO, pp. 12-24.

Churchill, C., Reinhard, D. and Qureshi, Z. (2006) 'Into action: microinsurance - report summary microinsurance conference', Munich, Washington and Geneva: Munich Re Foundation, CGAP Working Group on Microinsurance and ILO, January (online at: http://www.munichre-foundation.org/NR/ rdonlyres/A7C0E563-3F94-41A5-B7A7-1CAC19C85F96/0/IntoAction01_2006_Microinsurance_E.pdf ).

Danis, M., Biddle, A. and Goold, S. (2004) 'Enrollees choose priorities for medicare', The Gerontologist 44(1): 58-67, available online: http://gerontologist.gerontologyjournals.org/cgi/content/abstract/44/1/ 58 ,accessed 4 October 2005.

Danis, M., Binnendijk, E., Ost, A., Vellakkal, S., Koren, R. and Dror, D.M. (2006) 'Eliciting the health insurance Benefit choices of low-income populations in India with the CHAT exercise', submitted for publication in Health Services Management Research.

Derriennic, Y., Wolf, K. and Kiwanuka-Mukiibi, P. (2005) An Assessment of Community-Based Health Financing Activities in Uganda, Bethesda, MD: The Partners for Health Reformplus Project, Abt Associates Inc.

Devadasan, N., Ranson, K., Van Damme, W., Acharya, A. and Criel, B. (2006) 'The landscape of community health insurance in India: an overview based on 10 case studies', Health Policy 78(2-3): 224-234.

Dong, H., Kouyate, B., Cairns, J. and Sauerborn, R. (2005) 'Inequality in willingness-to-pay for communitybased health insurance', Health Policy 72(2): 149-156.

Dror, D.M. (2001) 'Reinsurance of health insurance for the informal sector', Bulletin of the World Health Organisation 79(7): 672-678.

Dror, D.M., Armstrong, J. and Kalavakonda, V. (2005a) 'Why micro health insurance schemes cannot forego reinsurance', Journal of Insurance and Risk Management (special issue on micro health insurance) (Greater Noida, India) 4(7): 1-29.

Dror, D.M. and Jacquier, Ch. (1999) 'Micro-insurance: extending health insurance to the excluded', International Social Security Review 52(1): 71-97.

Dror, D.M., Koren, R., Ost, A., Binnendijk, E., Vellakkal, S. and Danis, M. (2006a) 'Health insurance benefit packages prioritized by low-income clients in India: Three criteria to estimate effectiveness of choice, submitted for publication in Social Science and Medicine, May 2006. 
Dror, D.M., Koren, R. and Steinberg, D.M. (2006b) 'The impact of filipino micro health insurance units on income-related equality of access to healthcare', Health Policy 77(3): 304-317, doi:10.1016/j. healthpol.2005.08.001.

Dror, D.M. and Preker, A.S. (eds) (2002) Social Reinsurance: A New Approach to Sustainable Community Health Financing, Washington: World Bank \& ILO, pp xvii +518.

Dror, D.M., Radermacher, R. and Koren, R. (2006c) 'Willingness to pay for health insurance among rural and poor persons: field evidence from seven micro health insurance units in India', in Health Policy (in press), doi: 10.1016/j.healthpol.2006.07.11.

Dror, D.M., Soriano, E.S., Lorenzo, M.E., Sarol Jr., J.N., Azcuna, R.S. and Koren, R. (2005b) 'Field based evidence of enhanced healthcare utilization among persons insured by micro health insurance units in Philippines', Health Policy 73(3): 263-271.

Efron, B. (1979) 'Bootstrap method: another look at the jackknife', Annals of Statistics 7: 1-26.

Fairbank, A. (2003) Sources of Financial Instability of Community-Based Health Insurance Schemes: How Could Social Reinsurance Help?, Technical Report No. 024. Bethesda, MD: The Partners for Health Reformplus Project, Abt Associates Inc.

Feeley, F.G., Gasparro, D.J. and Snowden, K. (2002) 'Assessment of piloting social reinsurance in the Philippines', in D.M. Dror and A.S. Preker (eds) Social Reinsurance: A New Approach to Sustainable Community Health Financing, Washington: World Bank \& ILO, pp. 423-441.

Green, W.H. (1997) Econometric Analysis 3rd Edn, Upper Saddle River, NJ: Prentice Hall.

Gurenko, E.N. (2000) The Role of World Bank in Supporting Turkish Catastrophe Insurance Pool World Bank Conference on Innovations in Managing Catastrophic Risks, Washington DC http:// wwwl.worldbank.org/finance/assets/images/DCconference.pdf,accessed December 2004.

Habbani, K., Groot, W. and Jelovac, I. (2006) 'Household health-seeking behaviour in Khartoum, Sudan: the willingness to pay for public health services if these services are of good quality', Health Policy 75(2): $140-158$.

ILO (2002a) Extending Social Protection in Health Through Community-Based Health Organizations, Community-Based Schemes Working papers.

ILO (2002b) Micro-assurance santé: Guide d'introduction aux mutuelles de santé en Afrique, Guides and Manuals.

ILO/CGAP, (forthcoming) Book On Micro Finance, Geneva: ILO.

ILO/STEP (2003a) Micro Insurers: Inventory of Micro-Insurance Schemes in Bangladesh, Community-Based Schemes Working paper, Geneva.

ILO/STEP (2003b) An Inventory of Micro-Insurance Schemes in Nepal, Community-Based Schemes Working papers.

ILO/STEP (2003c) Extending maternity protection to women in the informal economy. An overview of community-based health-financing schemes, Community-Based Schemes Working papers, Geneva.

ILO/STEP (2005a) India: An inventory of micro insurance schemes Community-Based Schemes Working Paper no. 2, Geneva.

ILO/STEP (2005b) Inventory of Micro-Insurance Schemes in the Philippines, Community-Based Schemes Working paper no. 1, Geneva.

Loewenson, R. (1999) Public Participation in health: Making people matter, IDS Working Paper 84, available online: http://www.ids.ac.uk/ids/bookshop/wp/wp84.pdf,20 June 2005.

Miller Franco, L., Mbengue, C. and Atim, C. (2004) Social Participation in the Development of Mutual Health Organizations in Senegal, Bethesda, MD: The Partners for Health Reformplus Project, Abt Associates Inc, Available online: http://www.phrplus.org/Pubs/Tech056_fin.pdf [09.06.05].

Preker, A., Carrin, G., Dror, D.M., Jakab, M., Hsiao, W. and Arhin, D. (2002) 'Effectiveness of community health financing in meeting the cost of illness', Bulletin of the World Health Organization 80(2): 143-150, available online: http://www.scielosp.org/pdf/bwho/v80n2/a10v80n2.pdf, accessed 27 May 2005.

Radermacher, R. and Dror, I.H. (2006) 'Institutional options for delivering health insurance', chapter (4.4) in C. Churchill (ed) Protecting the Poor: A Microinsurance Compendium, Geneva: ILO, pp. 401-423.

Radermacher, R., Wig, N., van Putten-Rademaker, O., Müller, V. and Dror, D.M. (2005) Good and Bad Practices in Microinsurance: Yeshasvini Co-Operative Farmers Health Scheme, Karnataka, India, Report commissioned by ILO Social Finance Unit and CGAP, Sept 2005. 
Sachs, J. (Chairperson) (2001) Macroeconomics and Health: Investing in Health for Economic Development, Report of the Commission on Macroeconomics and Health, World Health Organization, Geneva, p. 60.

Selamet, Y. (nd) The Turkish Catastrophe Insurance Pool (TCIP) and the Compulsory Earthquake Insurance Scheme, available online: http://info.worldbank.org/etools/docs/library/114715/istanbul03/docs/istanbul03/11yazici3-n per cent5B1 per cent5D.pdf.

Swiss Re (2006) 'World Insurance 2005', Sigma Insurance Research 5/2006, http://www.swissre.com/ (accessed Jul 2006).

World Bank Institute (2004) 'Presentation of Agroasemex', http://www.worldbank.org/wbi/banking/ insurance/natdisaster/pdf/, accessed December 2004.

Zhang, L., Wang, H., Wang, L. and Hsiao, W. (2006) 'Social capital and farmer's willingness-to-join a newly established community-based health insurance in rural China', Health Policy 76(2): 233-242.

\section{About the Authors}

David Mark Dror, Ph.D. in Economics and Management (highest distinction) from Lyon 1 University, France and DBA (Magna cum Laude) in Health Services; hon. Professor of health insurance at Erasmus University Rotterdam Inst for Health Policy \& Management; "invited professor" of health economics at Clermont-Ferrand Univ. Inst for Development Studies (CERDI). Lead expert of the EU project "Strengthening micro health insurance units for the poor in India". Initiator and team leader of the Social Re project. Previously with ILO Social Protection Sector.

John Armstrong is an actuary and health economist with the Voluntary Health Insurance Board, Ireland. He has advised many governments and international organisations on health financing topics. He has a particular interest in micro health insurance and is Chief Technical Advisor to the Social Re Project. He is a Fellow of the Institute of Actuaries, the Society of Actuaries in Ireland, and the Royal Statistical Society. His university studies were undertaken in Trinity College Dublin and Georgetown University. 